\title{
Hand injuries in an older population - a retrospective cohort study from a single hand surgery centre
}

\author{
Olof Kringstad ${ }^{1}$, Lars B. Dahlin ${ }^{1,2}$ and Hans-Eric Rosberg ${ }^{1,2^{*}}$ (D)
}

\begin{abstract}
Background: Hand injuries occur at all ages. With an aging population globally an increasing number of hand injuries among the elderly is to be expected. The aim of the present study is to describe the health characteristics and detailed injury patterns for elderly with hand injuries, with incidence, as a background for further studies on the topic. Specific knowledge is currently lacking about hand injuries among this group. The study is a retrospective cohort study from a single hand surgery centre.

Methods: Data were collected for 286 patients, aged > 65 years, treated for traumatic hand injury between July 1 , 2013 and June 30, 2014 at the Department of Hand Surgery in Malmö.

Results: Incidence was 21.3/10000 inhabitants/year. The 286 patients included comprised 145 women and 141 men. The men had more severe injuries, often involving a wound, while women most commonly sustained a fracture after a fall. The men were younger than the women and required more surgery/admissions. Among all patients, $13 \%$ were healthy, while $27 \%$ patients took $\geq 5$ drugs, mainly for cardiovascular disease.

Conclusions: The incidence of hand injuries among the elderly is lower than among a younger population. Men sustained more wounds from using hazardous equipment, while women sustained post-fall fractures. A minority of the elderly is healthy. Prevention of fall injuries is crucial and emphasising safety awareness might reduce injuries in both sexes.
\end{abstract}

Keywords: Hand injury, Elderly, Incidence, Injury severity, Comorbidity

\section{Background}

Among the elderly, women injure their hands more often than men, commonly sustaining fractures due to falls [1]. Falling is the most common injury mechanism in people aged over 65 years, accounting for $75-79 \%$ of the traumas $[2,3]$. Approximately one third of the over-65 population fall every year [4] and one sixth fall repeatedly [5]. Studies show that $14 \%$ of the injuries among the elderly seen at emergency departments are to the upper extremities [3], while $29 \%$ of all injuries presenting at emergency departments are to the hand and wrist [6]. With the mean age of populations increasing in the developed and developing world, the number and proportion of elderly people will also increase [7]. Hence, an increasing number of injuries

\footnotetext{
* Correspondence: hanse.rosberg@med.lu.se

'Department of Hand Surgery, Skåne University Hospital, Jan Waldenströms gata 5, SE-205 02 Malmö, Sweden

${ }^{2}$ Department of Translational Medicine - Hand Surgery, Lund University, Malmö, Sweden
}

among the elderly can be expected [2]. Information is needed of the specific pattern of hand injuries that affect elderly. However, there are no such studies on elderly, focusing only on specific hand injuries in general and with details about the patient population. Such information may be relevant when planning how the resources should be used in the health care system in relation to the present different living patterns among elderly, i.e. more active at older age, which is highlighted in population studies [8].

More than $50 \%$ of older trauma patients suffer from cardiovascular disease [2]. Other conditions, such as balance difficulties, visual impairment and reduced cognitive capacity, may increase the risk of trauma and complicate subsequent treatment. Older trauma patients may make higher demands on the healthcare system than younger patients, due to a combination of increasing rates of both co-morbidity and poly-pharmacy, as a 
result of wider use of cardio-protective medicines, for example $[2,4,9]$.

Only one study has highlighted treatment of severe hand injuries among patients aged $>65$ years, concluding that age is no contraindication regarding replantation of fingers [10]. Healthcare consumption for injuries among the elderly is high, giving rise to substantial costs. Preventive measures would be beneficial in reducing these costs, avoiding overburdening of the healthcare system and reducing morbidity in this population [4, 11-14].

Our aim is to retrospective describe the health characteristics and detailed injury patterns for elderly with hand injuries in a cohort study from a single hand surgery centre, with a calculated incidence, as a background for further studies on the topic, since there is a lack of knowledge about specific hand injuries among the elderly.

\section{Methods}

\section{Subjects}

We included retrospectively all patients, older than 65 years, with a hand injury defined according to ICD-10 codes, from July 1, 2013 to June 30, 2014, who were treated at the Department of Hand Surgery in Malmö. The department treats patients with both minor and major hand injuries from the cities of Malmö and Lund in agreement with the involved health care providers in the region. The patients from Malmö and Lund are referred from their family doctor, or from the department of Orthopaedics or from the A\&E Department.

In 2013/14 the city of Malmö had a population of 426,849 of whom 66,736 were older than 65 years. Lund had a population of 220,979 with 35,343 people older than 65 years. The hand injury incidence will be calculated for both these two regions. The annual report (Statistics Sweden) for 2013 was used as December 31, 2013, which is the exact halfway point in the study period; hence provides an average statistical base to calculate the incidence.

Patients with major hand injuries, requiring specialized hand surgical care, including flexor tendon injuries and nerve injuries, are also referred to the department from the Southern healthcare region in Sweden with a population, in 2013/ 14 , of 1,741,584 including 323,954 people aged over 65 years.

\section{Variables}

Data were collected in a standardised manner for each patient from their medical records with the following variables: deceased or not, gender, age when injured, previous hand injuries, hand dominance, time and date of injury, injured side. Further data were also collected as follows.

\section{Co-morbidity}

For each patient the number of diagnoses was counted and those without any, explicitly mentioned in the records, were labelled healthy. Examples of diagnoses that were categorized, relevant from a hand condition and injury perspective, were cardiovascular and metabolic diseases, osteoarthritis, dizziness, visual impairment, psychiatric disorders, and osteoporosis.

\section{Number of pharmaceutical drugs}

The number of prescribed drugs was counted and the patients were divided into three groups $0,1-4$ and $\geq 5$ pharmaceutical drugs administered.

\section{Site of injury}

Sites of injury were grouped into carpal/forearm, rays 1 to 5 and multiple sites.

\section{Type of injury}

The main types of injuries were grouped into three categories: fractures, wounds and dislocations/ligament injuries.

\section{Injured structure}

Every injury was described according to the Modified Hand Injury Severity Score (MHISS) [15, 16].

\section{Injury severity}

MHISS was also used to score the severity of the injuries and to group them into four hand-injury categories: Minor $(<20)$, Moderate (21-50), Severe (51-100) and Major (> 100) $[15,16]$.

\section{Settings for injuries}

The settings in which the injuries took place were grouped into five categories: outdoors, home/indoors, when engaged in carpentry or handling firewood, at work, in/on a motor vehicle.

\section{Injury mechanism}

The injury mechanisms were grouped into six categories: fall of any kind, cut or saw, crush/avulsion, pull/punch/ twist, traffic accident and bite.

\section{Reason for injury}

If specified, the causes of the injury were grouped into six categories: tripping/stumbling/slipping, power-tools, animal, door/heavy object, glass and other sharp objects and cutting tools.

\section{Additional injuries}

Additional injuries that occurred in conjunction with the hand injuries were categorized into three main groups: wounds/contusions or fractures to the head, costal and vertebral fractures/compressions and lower-extremity fractures. 


\section{Treatment information}

Patients were categorized as being treated either as out-patients or in-patients. The type of treatment was recorded as either conservative (i.e. plaster or bandage) or operative (ranging from simple sutures to full scale surgery). The number of days spent on a hand surgical ward was counted for the in-patients and the number of visits to a hand surgeon, nurse and hand therapist for out-patients. Some patients with critical physical conditions were treated as in-patients on other wards; for these patients the hand surgical interventions were counted as out-patient visits due to the difficulty of determining how many in-patient days the hand injury alone would have required. Whether the eventual use of antibiotics was prophylactic or due to infection was noted. Complications comprised infection or other causes. The number of re-operations was grouped into 1,2 or more.

\section{Statistical methods}

Data are presented as a median [25th-75th percentiles] or numbers (\%). The Mann-Whitney U test was used for continuous variables, Pearson's Chi-square test and Fisher's exact test (in small sample groups) were used for categorical variables. A $p$-value of 0.05 or less was considered significant.

\section{Results}

\section{Incidence, gender, injured hand and time of injury}

Three hundred and ninety-eight patients were treated during the period of the study. Fifty-six patients were injured before July 1, 2013; 40 patients received treatment for conditions other than a traumatic hand or forearm injury; and 16 patients had only contusions. Thus, the remaining 286 patients were included; 217/286 (76\%) were treated as out-patients and 69/286 (24\%) as in-patients (Fig. 1).
One woman sustained two injuries during the study period. In the subsequent calculations she is counted as one patient, but each injury is considered separately. Consequently, 287 injuries are included. Nine men and seven women were no longer alive when the data were collected.

The overall incidence of traumatic hand injury in the elderly was 21.3/10000 inhabitants per year in the Malmö and Lund regions combined. Table 1 presents the number and the incidence of traumatic hand injuries for men and women in these regions, divided into 5-year age groups, showing a slight reduction in incidence as age increases.

Traumatic hand injuries occurred in equal proportions among elderly women and men in the two regions. More men than women were referred to the department from other regions; 28 women and 41 men $(p=0.02)$. Male patients were significantly younger than female $(p<0.01$; Table 2). Handedness was registered for only one third, 96/286, of the patients (Table 2). The left hand was more commonly injured than the right among both men $(p=0.05)$ and women $(p<0.01)$.

Most injuries occurred between 6 and $12 \mathrm{am}$, with fewer between 0 and 6 am (Fig. 2). Most injuries occurred in November and fewer in January and August (Fig. 3). The highest number of injuries occurred on Wednesdays and lowest on Mondays (Fig. 4).

\section{Co-morbidity and pharmaceutical drugs}

There was no documentation of co-morbidities for 26/ 286 (9\%) patients. Thirty-six (13\%) patients were healthy, while the most frequent diagnoses were cardiovascularmetabolic-endocrine diseases and osteoarthritis. One hundred and thirty (45\%) patients had hypertension and 96/286 (34\%) had cardiovascular diseases. Hypertension $(p=0.03)$, cardiovascular disease $(p<0.01)$, and diabetes mellitus type $2(p<0.01)$ were more common among men. Osteoarthritis of the hip and knee $(p=0.01)$,

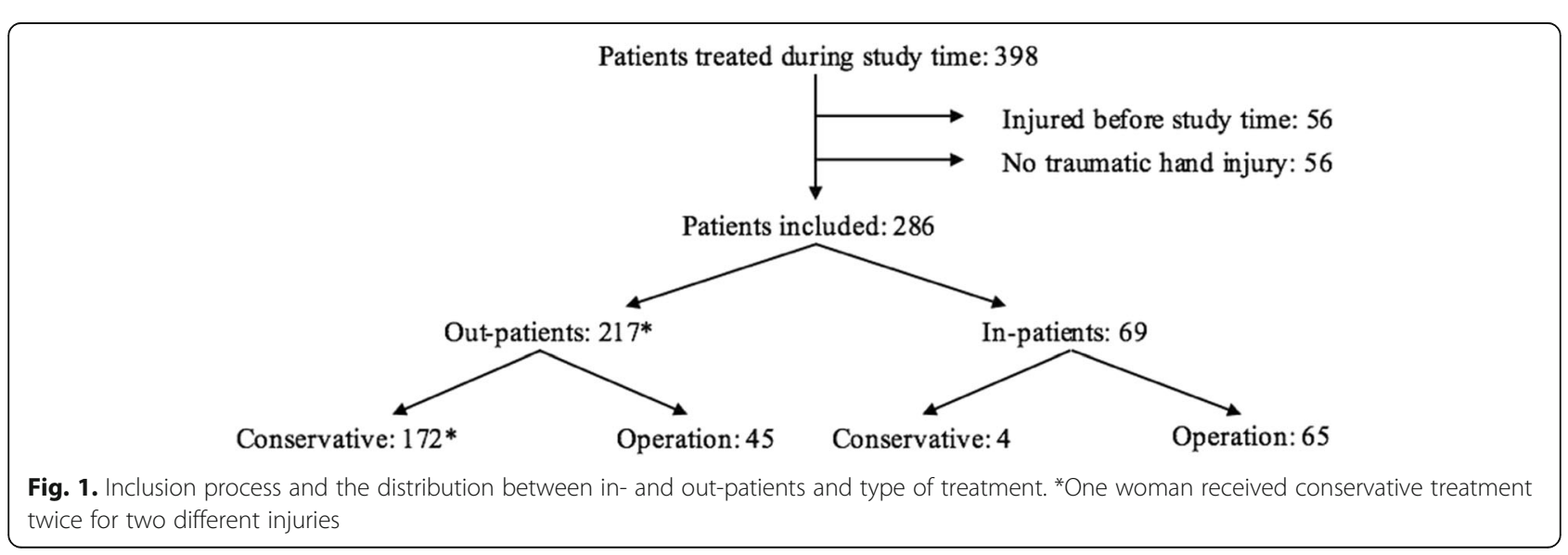


Table 1 The number of hand injuries and the incidence/10000 inhabitants and year

\begin{tabular}{lllllll}
\hline & \multicolumn{2}{l}{$l$} & & \multicolumn{2}{l}{ Malmö } & Total \\
\cline { 2 - 3 } Age (years) & Women & Men & & Women & Men & \\
\hline $66-70$ & $12(18.7)$ & $13(21.8)$ & & $24(21.8)$ & $30(29.2)$ & $79(23.4)$ \\
$71-75$ & $10(21.6)$ & $7(16.7)$ & & $22(26.1)$ & $19(25.6)$ & $58(23.3)$ \\
$76-80$ & $5(15.6)$ & $3(11.0)$ & & $20(30.1)$ & $11(21.3)$ & $39(22.0)$ \\
$81-85$ & $5(20.0)$ & $1(5.7)$ & & $9(16.5)$ & $13(36.6)$ & $28(21.1)$ \\
$86-90$ & $3(18.4)$ & $1(10.6)$ & $6(15.4)$ & $1(5.3)$ & $11(13.2)$ \\
$91-95$ & $1(12.1)$ & $1(33.6)$ & $1(5.2)$ & 0 & $3(8.1)$ \\
$\geq 96$ & 0 & 0 & 0 & 0 & 0 \\
Total & $36(18.5)$ & $26(16.3)$ & & $82(21.8)$ & $74(25.4)$ & $218(21.3)$ \\
\hline & & & & & &
\end{tabular}

osteoporosis $(p=0.01)$ and thyroid disorders $(p<0.01)$ were more common among women. Other diagnoses, interesting from a hand injury perspective, were dizziness, visually impaired, psychiatric disorders, dementia, and hand surgical disorders. The most frequent diagnoses are shown in Table 2.

There was no documentation of prescribed drugs for 45 / 286 (16\%) patients. The median number of drugs administered was 2 [1-5]. Twenty-two out of two hundred and eighty-six (8\%) patients had sustained earlier hand injuries.

\section{Site, type, injured structure and severity}

The most frequent site of injury was the 1st ray for men and the 5th ray for women. Fifty-two (18\%) injuries involved multiple sites (Table 3). Fractures were the most common type of injury among women, 97/146 (66\%), and wounds among men, 69/141 (49\%). The structure most frequently injured was the skin, followed by phalanges and metacarpal bones. Skin and nail-bed wounds were more common among men, while carpal and metacarpal fractures were more common among women. Five patients had only a forearm fracture, but were referred to the department due to suspected scaphoid fracture. Forearm fractures are not routinely followed up at the department, so this number is not representative for forearm fractures in this age group. Forty-two (15\%) injuries were to tendons, occurring more commonly among men $(p<0.01)$; $23 / 287$ (8\%) injuries were to digital nerves; and 5/287 (2\%) to main nerve trunks (Table 3 ).

The median MHISS was significantly higher for men than women $(p<0.01)$. The majority, 260/287 (90\%), of the injuries were minor or moderate (Table 3 ).

\section{Settings for injury}

Documentation concerning settings was missing for 68/ 287 (24\%) injuries. The most common settings for

Table 2 Characteristics for 286 patients with a hand injury treated at a department for hand surgery

\begin{tabular}{|c|c|c|c|c|}
\hline Patient characteristics & Women $n=145(51 \%)$ & Men $n=141(49 \%)$ & Total $n=286$ & $P$-value \\
\hline Age & 74 [70-79] & $71[68-76]$ & $72[69-78]$ & ${ }^{a}<0.01$ \\
\hline \multicolumn{5}{|l|}{ Co-morbidity } \\
\hline Healthy & $17(12 \%)$ & $19(13 \%)$ & $36(13 \%)$ & $\mathrm{b}_{0.65}$ \\
\hline Hypertension & $57(39 \%)$ & $73(52 \%)$ & $130(45 \%)$ & ${ }^{b} 0.03$ \\
\hline Cardiovascular disease & $38(26 \%)$ & $58(41 \%)$ & $96(34 \%)$ & b $<0.01$ \\
\hline Diabetes mellitus type 2 & $9(6 \%)$ & $26(18 \%)$ & $35(12 \%)$ & b $<0.01$ \\
\hline Pulmonary disease & $19(13 \%)$ & $15(11 \%)$ & $34(12 \%)$ & $\mathbf{b}_{0.52}$ \\
\hline Thyroid disorders & $25(17 \%)$ & $5(4 \%)$ & $30(10 \%)$ & b $<0.01$ \\
\hline Osteoarthritis & $21(14 \%)$ & $8(6 \%)$ & $29(10 \%)$ & ${ }^{b} 0.01$ \\
\hline Number of medicines & $2[1-5]$ & $3[1-6]$ & $2[1-5]$ & $c^{c} 0.13$ \\
\hline 0 & 27 (19\%) & $23(16 \%)$ & $50(17 \%)$ & $\mathbf{b}_{0.64}$ \\
\hline $1-4$ & $59(42 \%)$ & $54(38 \%)$ & $113(40 \%)$ & $\mathbf{b}_{0.75}$ \\
\hline$\geq 5(5-17)$ & $32(22 \%)$ & $46(33 \%)$ & $78(27 \%)$ & $\mathbf{b}_{0.09}$ \\
\hline Missing data & $27(19 \%)$ & $18(13 \%)$ & $45(16 \%)$ & $\mathbf{b}_{0.17}$ \\
\hline Previous hand injury & $10(7 \%)$ & $12(9 \%)$ & $22(8 \%)$ & ${ }^{\mathrm{b}} 0.61$ \\
\hline \multicolumn{5}{|l|}{ Handedness } \\
\hline Right & $44(30 \%)$ & $49(35 \%)$ & $93(33 \%)$ & $\mathbf{b}_{0.51}$ \\
\hline Left & $2(1 \%)$ & $2(1 \%)$ & $4(1 \%)$ & - \\
\hline Bimanual & $1(1 \%)$ & 0 & $1(0 \%)$ & - \\
\hline Missing & 98 (68\%) & 90 (64\%) & $188(66 \%)$ & $\mathbf{b}_{0.64}$ \\
\hline
\end{tabular}

Values are presented as number of patients (\% of patient group) or median [25th - 75th percentiles]. P-values represent differences between men and women in number of patients affected or median values by the use of ${ }^{a}$ Mann-Whitney $U$ test for continuous variables and ${ }^{b}$ Pearson's Chi-square test or ${ }^{c}$ Fisher's exact test (in small sample groups) for categorical variables 


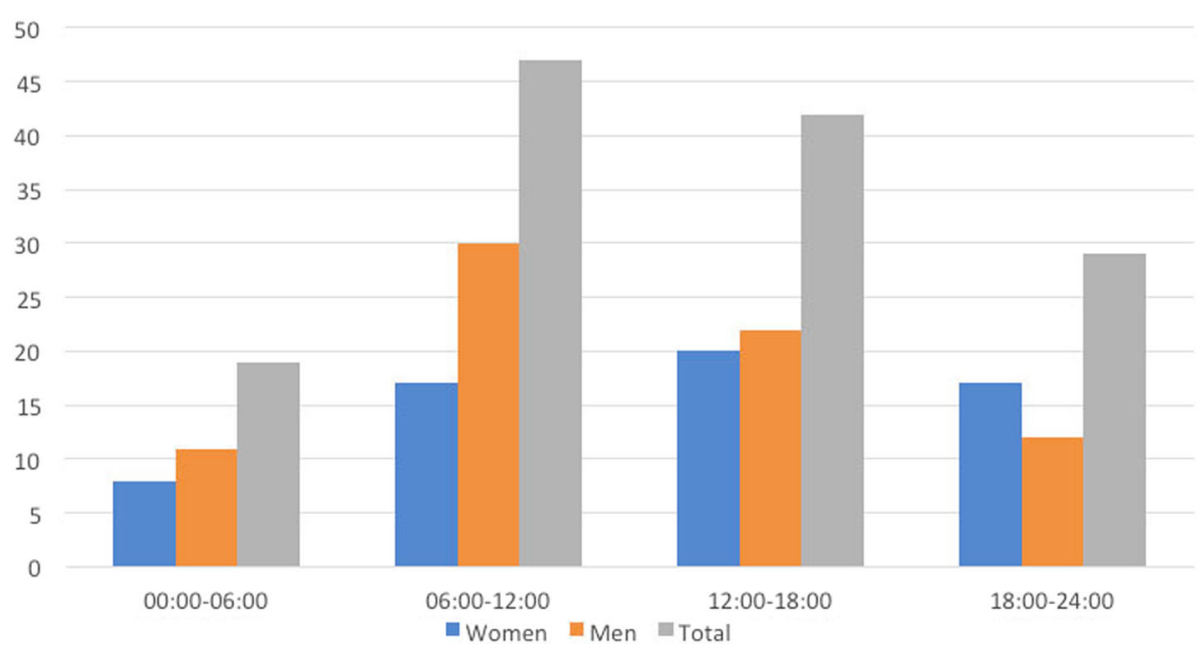

Fig. 2 Number of injuries in each quarter of the day. Data missing for 84 women and 66 men

injury, 95/287 (33\%), was outdoors, and women sustained more injuries outdoors than men $(p=0.05)$. More men than women $(p<0.01)$ incurred injuries while engaged in carpentry and handling firewood, 34/287 (12\%). Twelve out of one hundred and forty-one (9\%) men were injured at work and all the injuries were inflicted by power tools or heavy machinery (Table 4 ).

\section{Injury mechanism}

Falling was more common among women than men $(p<0.01)$ and also constituted (overall) the most common injury mechanism (153/287, 54\%). More men than women sustained cut or saw injuries $(p<0.01)$ and crush or avulsion injuries $(p=0.04)$. Tripping/ stumbling/slipping was overall the most frequent reason 63/287 (22\%) for injury. Accidents with power tools, 36/287 (13\%), were more common among men than women $(p<0.01)$. Four patients had cut themselves in suicide attempts. No specified reason was given for 113/287 (39\%) injuries, most of which were sustained by women. In 37/287 (13\%) injuries, additional body parts, particularly the head, were also injured (Table 4).

\section{Treatment}

More women were treated as out-patients and more men as in-patients $(p=0.03)$. Among the out-patients, men were younger $(p=0.03)$ than women and had a higher MHISS $(p=0.01)$. Most out-patients received conservative treatment; of those receiving operative

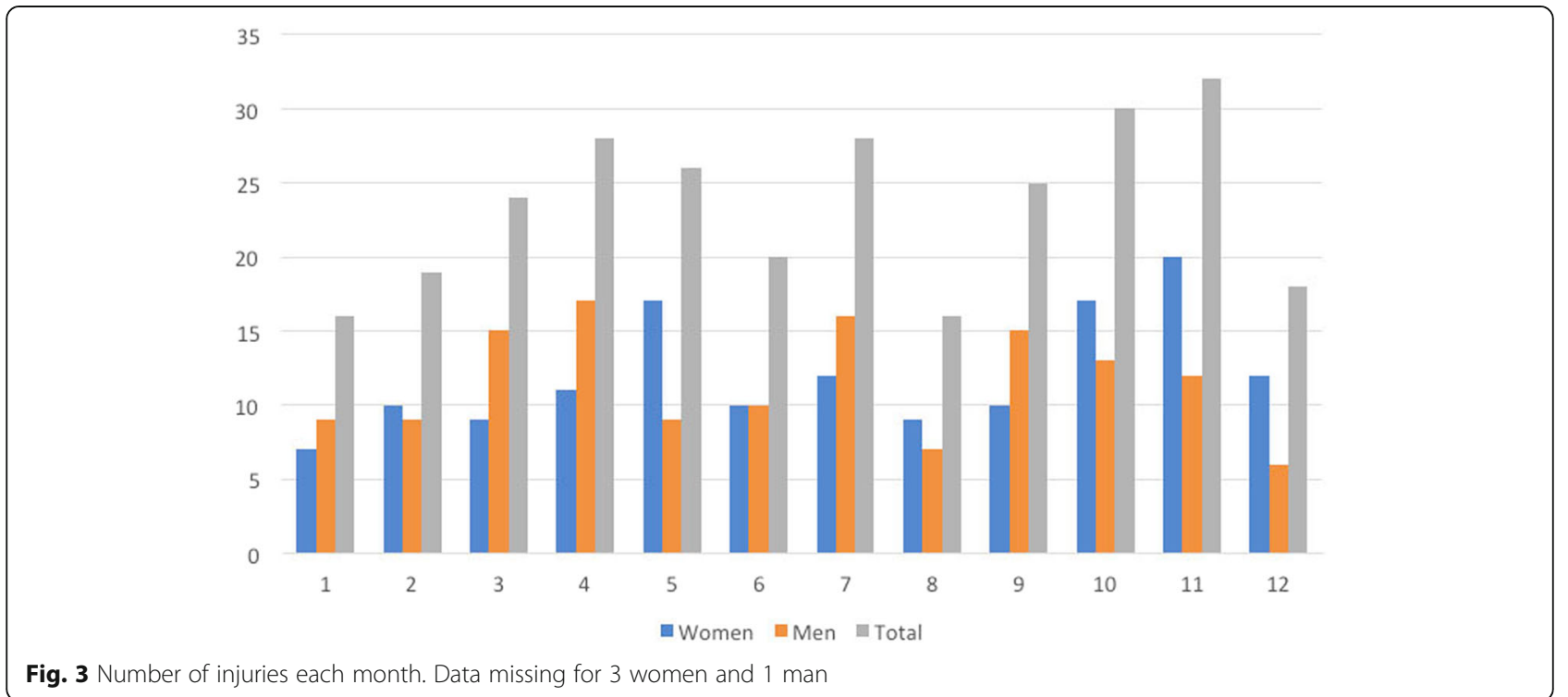




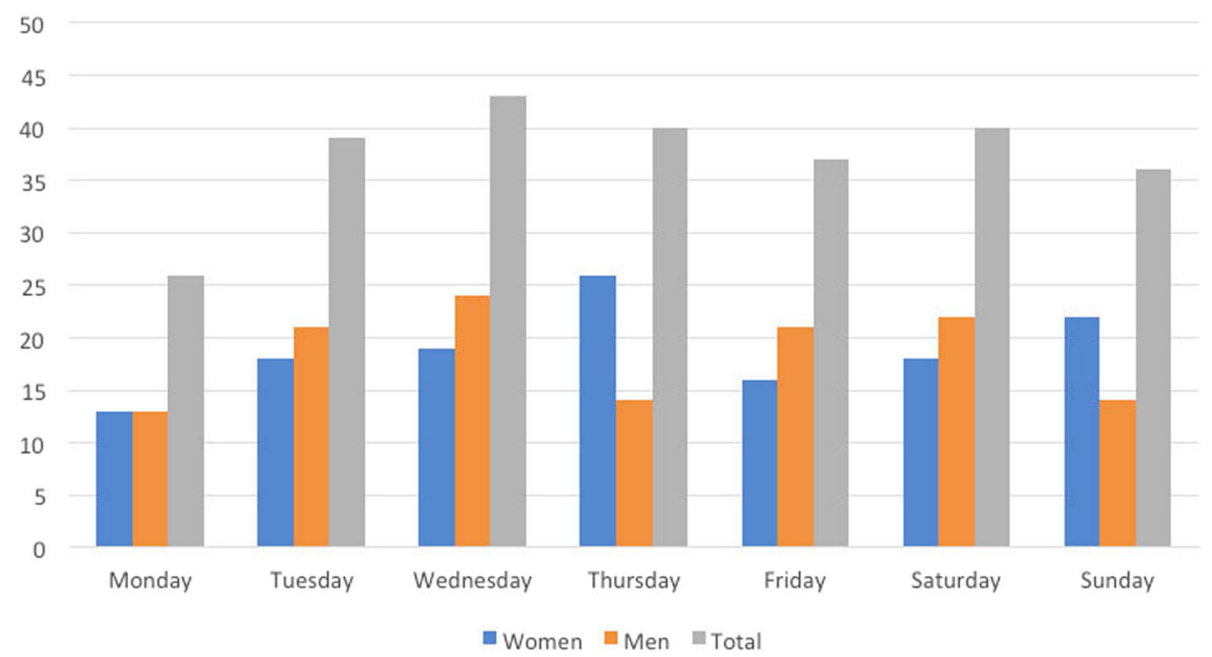

Fig. 4 Number of injuries each weekday. Data missing for 13 women and 12 men

treatment more were men $(p=0.02)$. The frequency of nurse visits $(p<0.01)$ and use of prophylactic antibiotics $(p<0.01)$ was higher among men, when treated as out-patients (Table 5). Male and female in-patients were similar regarding age and severity of injury and required the same amount of health care (Table 6).

\section{Discussion}

The present study shows that the incidence of hand injuries among the elderly was 21.3/10000 inhabitants and year. Hand injuries occurred to men and women equally, but men were younger than women at the time of injury. Interestingly, the type and severity also differed, with women sustaining fractures and men saw/cut/avulsion/ crush injuries; the latter more frequently requiring admission to hospital and surgery and reflected in higher MHISS. Only $13 \%$ of the patients were healthy, with hypertension and cardiovascular disease being the most frequent in those who had one or several diseases. Twenty-seven percent of the patients were prescribed $\geq 5$ drugs.

An earlier study, evaluating all age groups in our region, reported an incidence for hand injuries of 70/ 10000 inhabitants and year, where fractures were the most common injury (49\%) and falling was the most common mechanism (41\%) [1]. When only the injuries among patients aged 65 years or older in this earlier study were analysed, $55 \%$ were found to be fractures and women were more often injured than men. In contrast, the present study shows, when weighted for the number of men and women in this age group in the general population (which was not done in the previous study), that the same proportion of injuries occurred in elderly men and women. A study of 50,272 patients of all age groups in Denmark showed that only 19\% of the patients had fractures, but, unlike the present study, it also included contusions, which made up 19\% of the injuries [6]. In both of these studies, men sustained the largest number of injuries and the number of wounds was of the same magnitude as in the present study. The studies also showed a reduction in incidence with age. The findings to date show that the elderly do not injure their hands as often as younger patients, but they seem to experience a higher proportion of falls and related fractures.

The most common injury mechanism for fracture, especially in women, was a fall and in $63 / 153$ falls (41\%) tripping, stumbling or slipping was the cause. A previous study concerning all kinds of fall-related injuries [12] presents similar findings, where the same causes were also most common (28\%). In our study fall-related hand injuries affected twice as many women as men and a similar pattern has been observed in earlier studies [17]. In most cases no specified reasons are given for the rest of the falls. However, some patients fell due to standing on a bus that was braking or were pulled by a dog on a leash. Since fractures from falling constitute the most common injury, their further prevention using proven means, i.e. strength and balance training and vitamin D and calcium supplementation according to a large review of prevention of fall injuries [4], could possibly reduce the number of hand injuries in the elderly.

More men than women sustained injuries from powered wood splitters and circular saws, both of which caused more severe injuries [18-20]. Circular saw injuries occur in both experienced professionals and elderly patients, as recreational work is common also among older adults [18, 19]. Professionals, e.g. carpenters, injure their hands despite years of experience [18]. Traditionally, activities involving various power tools are more 
Table 3 Characteristics for the 287 injuries with a hand injury treated at a department for hand surgery

\begin{tabular}{|c|c|c|c|c|}
\hline Injury characteristics & Women $n=146$ & Men $n=141$ & Total $n=287$ & $P$-value \\
\hline \multicolumn{5}{|l|}{ Injured side } \\
\hline Right & $55(38 \%)$ & $56(40 \%)$ & $111(39 \%)$ & ${ }^{\mathrm{b}} 0.78$ \\
\hline Left & $87(60 \%)$ & 79 (56\%) & $166(58 \%)$ & ${ }^{\mathrm{b}} 0.69$ \\
\hline Bilateral & $4(3 \%)$ & $5(4 \%)$ & $9(3 \%)$ & - \\
\hline Missing & 0 & $1(1 \%)$ & $1(0 \%)$ & - \\
\hline \multicolumn{5}{|l|}{ Location of injury } \\
\hline Carpal hand/forearm & $27(18 \%)$ & $18(13 \%)$ & $45(16 \%)$ & ${ }^{\mathrm{b}} 0.22$ \\
\hline 1st ray & $18(12 \%)$ & $28(20 \%)$ & $46(16 \%)$ & ${ }^{b} 0.11$ \\
\hline 2nd ray & $9(6 \%)$ & $23(16 \%)$ & $32(11 \%)$ & ${ }^{\mathrm{b}} 0.01$ \\
\hline 3rd ray & $3(2 \%)$ & $6(4 \%)$ & $9(3 \%)$ & - \\
\hline 4th ray & $14(10 \%)$ & $16(11 \%)$ & $30(10 \%)$ & ${ }^{\mathrm{b}} 0.65$ \\
\hline 5th ray & $48(33 \%)$ & $25(18 \%)$ & $73(25 \%)$ & ${ }^{\mathrm{b}} 0.01$ \\
\hline Multiple parts & $27(18 \%)$ & $25(18 \%)$ & $52(18 \%)$ & ${ }^{\mathrm{b}} 0.88$ \\
\hline \multicolumn{5}{|l|}{ Type of injury } \\
\hline Fracture & $97(66 \%)$ & $50(35 \%)$ & $147(51 \%)$ & ${ }^{b}<0.01$ \\
\hline Wound & $34(23 \%)$ & $69(49 \%)$ & 103 (36\%) & ${ }^{b}<0.01$ \\
\hline Dislocation/ligament injury & $15(11 \%)$ & $22(16 \%)$ & $37(13 \%)$ & ${ }^{\mathrm{b}} 0.21$ \\
\hline \multicolumn{5}{|l|}{ Injured structures } \\
\hline \multicolumn{5}{|l|}{ Integument } \\
\hline Skin & $33(23 \%)$ & $54(38 \%)$ & $87(30 \%)$ & ${ }^{\mathrm{b}} 0.02$ \\
\hline Nail Bed & $8(5 \%)$ & $23(16 \%)$ & $31(11 \%)$ & ${ }^{b}<0.01$ \\
\hline \multicolumn{5}{|l|}{ Skeletal } \\
\hline Forearm fracture* & $4(3 \%)$ & $1(1 \%)$ & $5(2 \%)$ & - \\
\hline Carpal fracture & $17(12 \%)$ & $7(5 \%)$ & $24(8 \%)$ & ${ }^{b} 0.05$ \\
\hline Metacarpal fracture & $40(27 \%)$ & $20(14 \%)$ & $60(21 \%)$ & ${ }^{\mathrm{b}} 0.01$ \\
\hline Phalanx fracture & $34(23 \%)$ & $45(32 \%)$ & $79(28 \%)$ & ${ }^{b} 0.16$ \\
\hline Dislocation/ligament & $13(9 \%)$ & $21(15 \%)$ & $34(12 \%)$ & ${ }^{b} 0.14$ \\
\hline Multiple fractures and/or dislocations & $13(9 \%)$ & $8(6 \%)$ & $21(7 \%)$ & ${ }^{\mathrm{b}} 0.31$ \\
\hline Tendon & & & & ${ }^{b}<0.01$ \\
\hline Wrist flexor/extensor tendon & 0 & $5(4 \%)$ & $5(2 \%)$ & - \\
\hline Digital extensor tendon & $4(3 \%)$ & $11(8 \%)$ & $15(5 \%)$ & - \\
\hline Digital flexor tendon & $5(3 \%)$ & $11(8 \%)$ & $16(6 \%)$ & - \\
\hline Multiple tendon types & $2(1 \%)$ & $4(3 \%)$ & $6(2 \%)$ & - \\
\hline Nerve & & & & ${ }^{\mathrm{b}} 0.20$ \\
\hline Main nerve & $2(1 \%)$ & $3(2 \%)$ & $5(2 \%)$ & - \\
\hline Digital nerve/radial nerve branch & $9(6 \%)$ & $14(10 \%)$ & $23(8 \%)$ & - \\
\hline MHISS & $12.5[4-24.5]$ & $20[9.5-35.5]$ & 16 [6-30] & ${ }^{a}<0.01$ \\
\hline
\end{tabular}


Table 3 Characteristics for the 287 injuries with a hand injury treated at a department for hand surgery (Continued)

\begin{tabular}{lllll}
\hline Injury characteristics & Women $n=146$ & Men $n=141$ & Total $n=287$ & \\
\hline MHISS groups & & & & \\
Minor (1-20) & $104(71 \%)$ & $84(59 \%)$ & $188(65 \%)$ & ${ }^{\mathrm{b}} 0.22$ \\
Moderate (21-50) & $33(23 \%)$ & $39(28 \%)$ & $72(25 \%)$ & $\mathrm{b}^{\mathrm{b}} 0.39$ \\
Severe (51-100) & $6(4 \%)$ & $10(7 \%)$ & $16(6 \%)$ & $\mathrm{b}_{0.29}$ \\
Major (> 100) & $3(2 \%)$ & $8(6 \%)$ & $11(4 \%)$ & ${ }^{\mathrm{c}} 0.12$ \\
\hline
\end{tabular}

Values are presented as number of patients (\% of patient group) or median [25th - 75th percentiles]. P-values represent differences between men and women in number of patients affected or median values by the use of ${ }^{a}$ Mann-Whitney $U$ test for continuous variables and ${ }^{b}$ Pearson's Chi-square test or ${ }^{c}$ Fisher's exact test (in small sample groups) for categorical variables. Every injured structure is counted for each patient, i.e. several structures are scored for some patients and consequently sum of column percentage in the category Injured structure is not 100\%. *The number of forearm fractures is not representative for the entire population

common among men, which may explain the present observed difference. Such an argument is also valid for the crush injuries caused by heavy objects, e.g. farming equipment and heavy machinery, since men still engage more often in heavy work than women. Thus, as pointed out in earlier studies [21], the exercise of caution and more safety measures when working with these kinds of equipment cannot be stressed enough if hand injuries among older men are to be reduced.

A majority of the patients had minor or moderate injuries and could be treated as out-patients. Even when the data for out-patients were analysed separately, men had a higher MHISS, required surgery more often than women, required more nurse visits and consumed more

Table 4 Circumstances for the 287 injuries treated at a department for hand surgery

\begin{tabular}{|c|c|c|c|c|}
\hline Injury circumstances & Women $n=146$ & Men $n=141$ & Total $n=287$ & $P$-value \\
\hline \multicolumn{5}{|l|}{ Place for injury } \\
\hline Outdoors & $58(40 \%)$ & $37(26 \%)$ & $95(33 \%)$ & ${ }^{\mathrm{a}} 0.05$ \\
\hline Home/indoors & $34(23 \%)$ & $32(23 \%)$ & $66(23 \%)$ & ${ }^{\mathrm{a}} 0.92$ \\
\hline Carpentry/firewood handling & $5(3 \%)$ & $29(21 \%)$ & $34(12 \%)$ & ${ }^{a}<0.01$ \\
\hline Work & 0 & $12(9 \%)$ & $12(4 \%)$ & - \\
\hline Bus, car motor cycle & $7(5 \%)$ & $5(4 \%)$ & $12(4 \%)$ & ${ }^{\mathrm{a}} 0.61$ \\
\hline Missing data & $42(29 \%)$ & $26(18 \%)$ & $68(24 \%)$ & ${ }^{\mathrm{a}} 0.07$ \\
\hline \multicolumn{5}{|l|}{ Injury mechanism } \\
\hline Fall & $100(68 \%)$ & $53(38 \%)$ & $153(54 \%)$ & ${ }^{a}<0.01$ \\
\hline Cut or saw & $16(11 \%)$ & $41(29 \%)$ & $57(20 \%)$ & ${ }^{a}<0.01$ \\
\hline Crush or avulsion & $10(7 \%)$ & $21(15 \%)$ & $31(11 \%)$ & ${ }^{\mathrm{a}} 0.04$ \\
\hline Pull, punch, twist & $7(5 \%)$ & $14(10 \%)$ & $21(7 \%)$ & ${ }^{\mathrm{a}} 0.11$ \\
\hline Traffic & $9(6 \%)$ & $6(4 \%)$ & $15(5 \%)$ & ${ }^{\mathrm{a}} 0.48$ \\
\hline Bite & $4(3 \%)$ & $6(4 \%)$ & $10(3 \%)$ & ${ }^{b} 0.49$ \\
\hline \multicolumn{5}{|l|}{ Specific reason } \\
\hline Tripping/stumbling/slipping & $34(23 \%)$ & $29(21 \%)$ & $63(22 \%)$ & ${ }^{\mathrm{a}} 0.62$ \\
\hline Power tool & $6(4 \%)$ & $30(21 \%)$ & $36(13 \%)$ & ${ }^{a}<0.01$ \\
\hline Animal & $11(8 \%)$ & $14(10 \%)$ & $25(9 \%)$ & ${ }^{\mathrm{a}} 0.49$ \\
\hline Door/heavy object & $8(5 \%)$ & $12(9 \%)$ & $20(7 \%)$ & ${ }^{\mathrm{a}} 0.33$ \\
\hline Glass/other sharp object & $8(5 \%)$ & $8(6 \%)$ & $16(6 \%)$ & ${ }^{\mathrm{a}} 0.94$ \\
\hline Knife/axe/scissors & $5(3 \%)$ & $9(6 \%)$ & $14(5 \%)$ & ${ }^{\mathrm{a}} 0.26$ \\
\hline Missing data & $74(51 \%)$ & $39(28 \%)$ & $113(39 \%)$ & ${ }^{a}<0.01$ \\
\hline \multicolumn{5}{|l|}{ Other injuries } \\
\hline Head (wound, contusion, fracture) & $15(10 \%)$ & $10(7 \%)$ & $25(9 \%)$ & ${ }^{\mathrm{a}} 0.36$ \\
\hline Costal or vertebral fracture/compression & $2(1 \%)$ & $5(4 \%)$ & $7(2 \%)$ & - \\
\hline Lower extremity fracture & $4(3 \%)$ & $1(1 \%)$ & $5(2 \%)$ & - \\
\hline
\end{tabular}

Values are presented as number of patients (\% of patient group) or median [25th - 75th percentiles]. P-values represent difference between men and women in number of patients affected by the use of ${ }^{a}$ Pearson's Chi-square test or ${ }^{b}$ Fisher's exact test (in small sample groups) for the categorical variables 
Table 5 Treatment data for the 218 out-patients with a hand injury treated at a department for hand surgery

\begin{tabular}{|c|c|c|c|c|}
\hline \multicolumn{5}{|l|}{ Out-patients } \\
\hline Treatment & Women $n=119$ & Men $n=99$ & Total $n=218$ & $P$-value \\
\hline Age & 74 [70-79] & $71[68-77]$ & 73 [69-79] & ${ }^{\mathrm{a}} 0.03$ \\
\hline MHISS & $8[4-20]$ & 12 [6.5-23] & $12[4-20]$ & ${ }^{\mathrm{a}} 0.01$ \\
\hline Conservative & 105 (88\%) & $68(69 \%)$ & $173(79 \%)$ & ${ }^{\mathrm{b}} 0.11$ \\
\hline Operative & $14(12 \%)$ & 31 (31\%) & $45(21 \%)$ & ${ }^{\mathrm{b}} 0.02$ \\
\hline Operating time (minutes) & 37 [26-66] & $30[15-41.5]$ & 30 [15-45] & ${ }^{\mathrm{a}} 0.14$ \\
\hline Admitted after treatment & $7(6 \%)$ & $2(2 \%)$ & $9(4 \%)$ & ${ }^{c} 0.19$ \\
\hline \multicolumn{5}{|l|}{ Out-patient visits } \\
\hline Hand surgeon & $2[1-2]$ & $2[1-3]$ & $2[1-3]$ & ${ }^{\mathrm{a}} 0.14$ \\
\hline Nurse & $0[0-0]$ & $0[0-1.5]$ & $0[0-1]$ & ${ }^{\mathrm{a}}<0.01$ \\
\hline Hand therapist & $2[0-3]$ & $1[0-2]$ & $1[0-3]$ & ${ }^{\mathrm{a}} 0.08$ \\
\hline \multicolumn{5}{|l|}{ Antibiotics } \\
\hline Prophylaxis & $15(13 \%)$ & $30(30 \%)$ & $45(21 \%)$ & ${ }^{b}<0.01$ \\
\hline Due to infection & $3(3 \%)$ & $8(8 \%)$ & $11(5 \%)$ & ${ }^{\circ} 0.07$ \\
\hline \multicolumn{5}{|l|}{ Complications } \\
\hline Infection & $4(3 \%)$ & $6(6 \%)$ & $10(5 \%)$ & - \\
\hline Other & $1(1 \%)$ & $1(1 \%)$ & $2(1 \%)$ & - \\
\hline \multicolumn{5}{|l|}{ Re-operations } \\
\hline 1 & 0 & $2(2 \%)$ & $2(1 \%)$ & - \\
\hline 2 or more & 0 & 0 & 0 & - \\
\hline
\end{tabular}

Values are presented as number of patients (\% of patient group) or median [25th - 75th percentiles]. P-values represent differences between men and women in number of patients affected or median values by the use of ${ }^{a}$ Mann-Whitney $U$ test for continuous variables and ${ }^{b}$ Pearson's Chi-square test or ${ }^{c}$ Fisher's exact test (in small sample groups) for categorical variables

prophylactic antibiotics, which is reasonable in light of the more severe and open injuries. More men than women were also admitted to hospital among the patients from the Malmö/Lund regions and from the other regions. However, when the data for the in-patients were analysed separately, men and women did not differ regarding MHISS, operating time, days on the ward and number of out-patient visits. Taken together, these overall data indicate that hand injuries among men are more expensive to treat than those among women.

The observed age difference, with men being younger than women at time of injury, could possibly be explained by the fact that men may still be more active using e.g. power tools during their leisure time or still in a partial professional life in spite of their age. At a higher age one may anticipate that most men decrease their use of hazardous equipment. A consequence of aging, e.g. osteoporosis, especially among women may contribute to observation that women had a higher age at injury. The decrease in overall incidence with age is probably, for several reasons, a result of reduced activity and, thus, less exposure to potentially injurious mechanisms. Osteoporosis was, as expected, more common among women than men. One extensive study on hand fractures concludes that, until retirement, men have a higher relative risk of sustaining hand fractures due to a riskier lifestyle, but after the age of 65 the relative risk is higher for women [22]. That study also found that the most common fractures of the hand are to the metacarpals and phalanges [22]. This is confirmed by the present findings, where women had more fractures than men and the most common damage was to the phalanges and metacarpals. A nationwide study of fall-related injuries from the Netherlands shows that, in comparison with hand/finger fractures, hip fractures were more than four times as common, and wrist fractures $40 \%$ more common [13].

Our finding that $58 \%$ of the injuries affected the left hand contradicts previous studies in all age groups, where the right hand was more commonly injured, except in cases of work-related hand injuries to right-handed patients [23]. Injuries at work, as well as when engaged in carpentry and handling firewood, were common among men. These latter injuries are comparable to work-related injuries, which might explain the high incidence of left-hand injuries occurring in men. Other studies of severe hand injuries, mainly from saws and machines, also reported an over-representation of left-hand injuries $[24,25]$. In older women, the dominant handgrip strength is significantly reduced after the 
Table 6 Treatment data for the 69 in-patients with a hand injury treated at a department for hand surgery

\begin{tabular}{|c|c|c|c|c|}
\hline \multicolumn{5}{|c|}{ In-patients in hand surgical ward (other ward) } \\
\hline Treatment & Women $n=27$ & Men $n=42$ & Total $n=69$ & P-value \\
\hline Age & 73 [70-79] & $70.5[68-73]$ & $71[68-75]$ & ${ }^{\mathrm{a}} 0.07$ \\
\hline MHISS & $32[19-58]$ & $34[20-74]$ & $32[20-66]$ & ${ }^{\mathrm{b}} 0.35$ \\
\hline Conservative & $2(7 \%)$ & (2) $(5 \%)$ & $2(2)(6 \%)$ & ${ }^{c} 0.66$ \\
\hline Operative & $24(1)(93 \%)$ & $36(4)(95 \%)$ & $60(5)(94 \%)$ & ${ }^{\mathrm{b}} 0.91$ \\
\hline Operating time (minutes) & $61[48-90]$ & $64[40.5-105]$ & $62[48-98]$ & ${ }^{\mathrm{a}} 0.81$ \\
\hline Days in ward & $3[2-4]$ & $2.5[2-4]$ & $3[2-4]$ & ${ }^{\mathrm{a}} 0.88$ \\
\hline Admitted after treatment & 0 & $2(5 \%)$ & $2(3 \%)$ & ${ }^{c} 0.52$ \\
\hline \multicolumn{5}{|l|}{ Out-patient visits } \\
\hline Hand surgeon & $2[1-3.5]$ & $2[1-3]$ & $2[1-3]$ & ${ }^{\mathrm{a}} 0.57$ \\
\hline Nurse & $1[1-3]$ & $2[1-3]$ & $2[1-3]$ & ${ }^{\mathrm{a}} 0.37$ \\
\hline Hand therapist & $3[0.5-7]$ & $3[0-6]$ & $3[0-7]$ & ${ }^{\mathrm{a}} 0.66$ \\
\hline \multicolumn{5}{|l|}{ Antibiotics } \\
\hline Prophylaxis & 17 (63\%) & $34(81 \%)$ & $51(74 \%)$ & ${ }^{\mathrm{b}} 0.40$ \\
\hline Due to infection & $4(15 \%)$ & $4(10 \%)$ & $8(12 \%)$ & - \\
\hline \multicolumn{5}{|l|}{ Complications } \\
\hline Infection & $5(19 \%)$ & 7 (17\%) & 12 (17\%) & - \\
\hline Other & $2(7 \%)$ & $2(5 \%)$ & $4(6 \%)$ & - \\
\hline \multicolumn{5}{|l|}{ Re-operations } \\
\hline 1 & $1(4 \%)$ & $3(7 \%)$ & $4(6 \%)$ & - \\
\hline 2 or more & $2(7 \%)$ & $2(5 \%)$ & $4(6 \%)$ & - \\
\hline
\end{tabular}

Values are presented as number of patients (\% of patient group) or median [25th - 75th percentiles]. P-values represent differences between men and women in number of patients affected or median values by the use of ${ }^{a}$ Mann-Whitney $U$ test for continuous variables and ${ }^{b}$ Pearson's Chi-square test or ${ }^{C}$ Fisher's exact test (in small sample groups) for categorical variables. For number of patients with conservative and operative treatment, the numbers in the table indicates treatment at a "hand surgical ward" and in "an(other ward)"

age of 60 , and that of the non-dominant handgrip after the age of 50 [26]. The dominant hand is used more often in activities of daily living and hence is stronger and may not fracture as easily as the non-dominant. In older women, reduced handgrip strength is an independent risk factor for osteoporotic fractures [27]. Another study shows that the correlation between non-dominant handgrip strength and frailty is stronger than that between the dominant handgrip strength and frailty [28], indicating that the dominant hand is stronger than the body in general. This might explain the high incidence of left-hand injuries in women. Notably, handedness was poorly documented, making it difficult to draw conclusions from a correlation between handedness and injured side.

The population of older adults in society is increasing as are the numbers of medicines they take. The increase in medication for treatment of various diseases is partly due to more widespread use of cardio-protective medicines and anti-depressants [9]. Patients prescribed more medicines are more likely to have more co-morbidities, more limitations in the activities of daily living and less mental capacity as well as to consume more healthcare than those taking fewer medicines [9]. The influence of side effects of the various medications cannot be excluded, e.g. the risk of orthostatic hypotension in connection with antidepressant treatments. Twenty-seven percent of the present patients took $\geq 5$ drugs, involving the risk of interaction between the different medicines and of side effects. Forty-five per cent of the patients suffered from hypertension and 34\% from cardiovascular disease, which is in line with previous findings of co-morbidities in older trauma patients [2]. Considering co-morbidities, medicines and the biological repair processes, repair and reconstruction after a hand injury may be more challenging in elderly patients.

Hand injuries potentially leave the patients with long-term disabilities and functional limitations. Since older people already suffer from a decline in physical and mental capacity they are vulnerable to these consequences and may be in need of additional support after hand injuries. Previous studies have researched the outcome of hand injuries and conclude that a higher severity grade of hand injury correlates with greater costs, longer sick leave and reduced hand function, but that even minor injuries can be debilitating $[24,25,29]$. The 
outcomes of hand injuries among the elderly have not yet been studied, but the consequences for older patients are likely to affect their ability to engage in daily living and leisure activities. Hence, there is a potential gain from conducting more studies on the topic both in terms of improving the quality of life for the elderly with hand injuries and reducing the costs to society.

There are a number of limitations to this study. The retrospective design precludes any completion of missing data. Some patients with minor hand injuries may have been treated by their general practitioners without referral, despite an established routine for the following up of all hand injuries at our department, meaning that we cannot be sure that all hand injuries were included. As many hand injuries can be treated without knowledge of the patients' co-morbidities or medicines; thus, documentation of these was sometimes scarce. We believe that it is important for healthcare providers to improve the recording of patient demographics, co-morbidity, handedness etc. with respect to planning of the resources in the health care system. The administrative system for medical records in the primary healthcare and hospital sectors differs and without access to medical records from the primary care sector some co-morbidities and medicines may have been missed. There might be a potential bias when calculating the incidence, which might be underestimated. However, in the present region there is an agreement and specific routines for long with GPs, A\&E units and department of Orthopaedics how to refer patients with hand injuries, resulting in that most injuries are treated at the present department.

\section{Conclusions}

In comparison with younger patients, older men and women do not injure their hands as often and the proportion of men and women sustaining injuries is equal. Men are younger at injury, sustain more wounds from hazardous equipment and, thus, have more severe injuries. Women usually fall and fracture their hands. Fall-prevention seems to be most important for reducing injuries among older women, emphasising safety precautions might reduce the injuries among men. A minority of the elderly is healthy, which may complicate treatment. Further studies are needed to examine the outcomes of hand injuries among the elderly.

\section{Abbreviations}

MHISS: Modified Hand Injury Severity Score

\section{Acknowledgements}

Not applicable.

Funding

This work was support by the Swedish Research Council (Medicine); the Faculty of Medicine, Lund University; Region Skåne, Capio Forskningsstiftelse,
Stiftelsen Ragnhild och Einar Lundströms Minne and Stiftelsen Sigurd och Elsa Goljes Minne. The funding body was involved in the collection, analysis and interpretation of data by supporting with salary for the time needed. They were not involved in the design or writing the manuscript.

\section{Availability of data and materials}

Public access to the data is restricted by the Swedish Authorities (Public Access to Information and Secrecy Act; https://www.government.se/ information-material/2009/09/public-access-to-information-and-secrecy-act/), but data can be made available for researchers after a special review that includes approval of the research project by both an Ethics Committee and the authorities' data safety committees.

\section{Authors' contribution}

LBD and HER were involved in the planning of the study. OK and HER collected and analyzed the data. OK, LBD and HER contributed equal in writing the manuscript. All authors read and approved the final manuscript.

\section{Ethics approval and consent to participate}

The study was approved by the Regional Ethical Review Board in Lund, Sweden (Ethical permission no 2015/832). A written human subject consent was not considered necessary in this study according to the committee. The study was a retrospective study including only information from the patients' files and therefore no consent was needed from each of the patients. The study was approved by the ethic committee in this way.

\section{Consent for publication}

Not applicable.

\section{Competing interests}

The authors declare that they have no competing interests.

\section{Publisher's Note}

Springer Nature remains neutral with regard to jurisdictional claims in published maps and institutional affiliations.

Received: 10 October 2018 Accepted: 6 May 2019

Published online: 24 May 2019

\section{References}

1. Rosberg HE, Dahlin LB. Epidemiology of hand injuries in a middle-sized city in southern Sweden: a retrospective comparison of 1989 and 1997. Scand J Plast Reconstr Surg Hand Surg. 2004;38:347-55.

2. Bonne S, Schuerer DJ. Trauma in the older adult. epidemiology and evolving geriatric trauma principles Clin Geriatr Med. 2013;29:137-50.

3. Kara H, Bayir A, Ak A, Akinci M, Tufekci N, Degirmenci S, Azap M. Trauma in elderly patients evaluated in a hospital emergency department in Konya, Turkey: a retrospective study. Clin Interv Aging. 2014;9:17-21.

4. Kannus $P$, Sievanen $H$, Palvanen M, Jarvinen T, Parkkari J. Prevention of falls and consequent injuries in elderly people. Lancet. 2005;366:1885-93.

5. Chen JS, Simpson JM, March LM, Cameron ID, Cumming RG, Lord SR, Seibel MJ, Sambrook PN. Risk factors for fracture following a fall among older people in residential care facilities in Australia. J Am Geriatr Soc. 2008;56: 2020-6.

6. Angermann $\mathrm{P}$, Lohmann M. Injuries to the hand and wrist. A study of 50,272 injuries. J Hand Surg (Br). 1993;18:642-4.

7. United Nations. World population prospects, the 2015 revision. New York: Key Findings and Advance Tables. In; 2015.

8. Rydberg Sterner T, Ahlner F, Blennow K, Dahlin-Ivanoff S, Falk H, Havstam Johansson L, Hoff M, Holm M, Horder H, Jacobsson T, et al. The Gothenburg H70 birth cohort study 2014-16: design, methods and study population. Eur J Epidemiol. 2019;34:191-209.

9. Charlesworth CJ, Smit E, Lee DS, Alramadhan F, Odden MC. Polypharmacy among adults aged 65 years and older in the United States: 1988-2010. J Gerontol A Biol Sci Med Sci. 2015;70:989-95.

10. Barzin A, Hernandez-Boussard T, Lee GK, Curtin C. Adverse events following digital replantation in the elderly. J Hand Surg Am. 2011;36:870-4.

11. Rizzo JA, Friedkin R, Williams CS, Nabors J, Acampora D, Tinetti ME. Health care utilization and costs in a Medicare population by fall status. Med Care. 1998:36:1174-88. 
12. Roudsari BS, Ebel BE, Corso PS, Molinari NA, Koepsell TD. The acute medical care costs of fall-related injuries among the U.S. older adults. Injury. 2005;36: 1316-22.

13. Hartholt KA, Polinder S, Van der Cammen TJ, Panneman MJ, Van der Velde $\mathrm{N}$, Van Lieshout EM, Patka P, Van Beeck EF. Costs of falls in an ageing population: a nationwide study from the Netherlands (2007-2009). Injury. 2012:43:1199-203.

14. Stevens JA, Corso PS, Finkelstein EA, Miller TR. The costs of fatal and nonfatal falls among older adults. Inj Prev. 2006;12:290-5.

15. Urso-Baiarda F, Lyons RA, Laing JH, Brophy S, Wareham K, Camp D. A prospective evaluation of the modified hand injury severity score in predicting return to work. Int J Surg. 2008;6:45-50.

16. Campbell DA, Kay SP. The hand injury severity scoring system. J Hand Surg (Br). 1996;21:295-8.

17. Stevens JA, Sogolow ED. Gender differences for non-fatal unintentional fall related injuries among older adults. Inj Prev. 2005;11:115-9.

18. Frank M, Hecht J, Napp M, Lange J, Grossjohann R, Stengel D, Schmucker U, Ekkernkamp A, Hinz P. Mind your hand during the energy crunch: functional outcome of circular saw hand injuries. J Trauma Manag Outcomes. 2010;4:11.

19. Hoxie SC, Capo JA, Dennison DG, Shin AY. The economic impact of electric saw injuries to the hand. J Hand Surg Am. 2009;34:886-9.

20. Lindqvist A, Gerdin B. Hand injury from powered wood splitters. Scand J Plast Reconstr Surg Hand Surg. 2008:42:246-52.

21. Eriksson M, Karlsson J, Steen Carlsson K, Dahlin LB, Rosberg HE. Economic consequences of accidents to the hands and forearms by log splitters and circular saws: cost of illness study. J Plast Surg Hand Surg. 2011;45:28-34.

22. Feehan LM, Sheps SB. Incidence and demographics of hand fractures in British Columbia, Canada: a population-based study. J Hand Surg Am. 2006; 31:1068-74.

23. Beaton AA, Williams L, Moseley LG. Handedness and hand injuries. J Hand Surg (Br). 1994;19:158-61.

24. Mink van der Molen AB, Ettema AM, Hovius SE. Outcome of hand trauma: the hand injury severity scoring system (HISS) and subsequent impairment and disability. J Hand Surg Br. 2003:28:295-9.

25. Rosberg HE, Carlsson KS, Cederlund Rl, Ramel E, Dahlin LB. Costs and outcome for serious hand and arm injuries during the first year after trauma - a prospective study. BMC Public Health. 2013;13:501.

26. Ditroilo M, Forte R, Benelli P, Gambarara D, De Vito G. Effects of age and limb dominance on upper and lower limb muscle function in healthy males and females aged 40-80 years. J Sports Sci. 2010;28:667-77.

27. Albrand G, Munoz F, Sornay-Rendu E, DuBoeuf F, Delmas PD. Independent predictors of all osteoporosis-related fractures in healthy postmenopausal women: the OFELY study. Bone. 2003;32:78-85.

28. Theou O, Jones GR, Jakobi JM, Mitnitski A, Vandervoort AA. A comparison of the relationship of 14 performance-based measures with frailty in older women. Appl Physiol Nutr Metab. 2011;36:928-38.

29. Rosberg HE, Carlsson KS, Dahlin LB. Prospective study of patients with injuries to the hand and forearm: costs, function, and general health. Scand J Plast Reconstr Surg Hand Surg. 2005;39:360-9.

Ready to submit your research? Choose BMC and benefit from:

- fast, convenient online submission

- thorough peer review by experienced researchers in your field

- rapid publication on acceptance

- support for research data, including large and complex data types

- gold Open Access which fosters wider collaboration and increased citations

- maximum visibility for your research: over $100 \mathrm{M}$ website views per year

At BMC, research is always in progress.

Learn more biomedcentral.com/submissions 